\title{
Adult-Onset Severe Hypocalcemia Due Defect in Parathyroid Calcium-Sensing Receptors
}

\author{
Kamel El-Reshaid ${ }^{* 1}$, Shaikha Al-Bader ${ }^{2}$ \\ ${ }^{1}$ Department of Medicine, Faculty of Medicine, Kuwait University \\ ${ }^{2}$ Department of Medicine, Nephrology Unit, Amiri Hospital, Ministry of Health, Kuwait \\ Corresponding author: Kamel El-Reshaid; MB Bch, Am B Med, Am B Nephrology, FRCP (Ed); kamel@hsc.edu.kw \\ Received 03 May 2020; \\ Accepted 16 June 2020; \\ Published 04 July 2020
}

\begin{abstract}
Parathyroidectomy, of the 4 glands, with/without thyroidectomy is the most common cause of hypoparathyroidism. Autoimmunity is a rare etiology, either as an isolated endocrinopathy or as a component of autoimmune polyglandular syndrome 1 (APS 1). In this case report; we describe a patient with an adult-onset hypoparathyroidism and discuss its pathophysiology in relation to calcium-sensing receptors in addition to its diagnostic work up and management.
\end{abstract}

Keywords: Autoimmune, autoimmune polyglandular syndrome 1, calcium-sensing receptors, hypocalcemia, hypoparathyroidism, vitamin D, urolithiasis.

\section{Introduction}

Hypocalcemia is a manifestation of parathyroid disease. The latter can result from defect in parathyroid calcium-sensing receptors and/or parathyroid lesions ${ }^{[1]}$. Hypoparathyroidism (HP) is usually caused by surgical removal of all four parathyroid glands. Autoimmunity is a rare cause of $\mathrm{HP}^{[2]}$. The latter develops as an isolated disease or as part of an autoimmune polyendocrine syndrome $1^{[3]}$. In this case report; we describe a patient with an adult-onset isolated HP and discuss its pathophysiology, diagnostic work up and management.

\section{Case report}

A 25-year-woman presented with history of numbness and twitches of the hands, feet and lips for 2 months. The patient did not have past history of significant medical illness, allergy or chronic intake of medications. Her initial physical examination did not show abnormality except for muscle cramps, facial twitches and irritability. Chovetek's and Trousaeau's signs were positive. Laboratory tests showed normal peripheral leucocytic and platelets counts. Hemoglobin was normal at $120 \mathrm{~g} / \mathrm{L}$. Serum sugar, urea, creatinine, electrolytes and liver functions were normal except for low corrected serum calcium (Ca) at $1.5 \mathrm{mmol} / \mathrm{L}$ and magnesium at $0.5 \mathrm{mmol} / \mathrm{L}$. Serum phosphorus was $1.5 \mathrm{mmol} / \mathrm{L}$. TSH was normal. Urine routine and microscopy did not show abnormality. Chest $\mathrm{x}-$ ray and ECG were normal. Ultrasound of the kidneys, adrenal, thyroid and parathyroid glands was normal. Intact parathyroid hormone (PTH), by immunoassay (ARCHITECT-Abbott labs); was at upper limit of normal at $6 \mathrm{pmol} / \mathrm{L}$ with normal range 1.6-6.9 $\mathrm{pmol} / \mathrm{L}^{[4]}$. Vitamin B12 and 1, 25 dihydroxyvitamin D (VD3) were normal at $591 \mathrm{pg} / \mathrm{ml}$ (normal: 201-804) and $129 \mathrm{nmol} / \mathrm{L}$ (normal: 125-175), respectively. Morning serum cortisol, was $343 \mathrm{nmol} / \mathrm{L}$ (normal: 138-635) and cosyntropin stimulation test showed normal response of adrenal gland. On unrestricted diet; her mineral metabolic screen (MMS) showed normal tubular reabsorption of phosphorus and Ca with 24-h urinary Ca excretion at upper limit of normal at $220 \mathrm{mg}$ (normal: < 250). Moreover, MMS showed normal creatinine clearance with normal uric acid, oxalate and cysteine excretion and adequate citrate level. Bone densimetry was normal. She was treated with increasing doses of oral $\mathrm{Ca}$ and 1 hydroxycholecaciferol (One alpha) to relieve her muscle twitches and maintain serum $\mathrm{Ca}$ at 2-2.3 $\mathrm{mmol} / \mathrm{L}$. Finally she was stable at Ca carbonate $1.2 \mathrm{mg}$ thrice daily with One alpha $1 \mathrm{ug}$ daily. Two weeks after stabilization of her drug therapy, MMS was repeated. Urinary Ca excretion was $320 \mathrm{mg} / \mathrm{day}$. After 5 years of follow up, she remained asymptomatic yet dependent on the same drugtherapy. Serum Ca, parathyroid hormone, vitamin D any $24 \mathrm{~h}-$ urinary $\mathrm{Ca}$ remained normal. Follow up ultrasound did not show evidence of stone disease or nephrocalcinosis. Bone mineral density remained normal.

\section{Discussion}

Ca homeostasis is regulated in the gut, kidneys, and bone by PTH and VD3. Approximately $99 \%$ of the body $\mathrm{Ca}$ is contained in bones. In healthy individuals, daily bone resorption and formation exchange $<1 \%$ with extracellular Ca. Normally $10 \%$ of the 
extracellular $\mathrm{Ca}$ is lost in the urine; since $60 \%$ is not protein bound and hence; is freely filtered through the renal glomeruli. Subsequently, $80 \%$ is passively reabsorbed in the proximal convoluted tubules and $10 \%$ in the thick ascending limb of Henle by the action of PTH. To maintain normal serum $\mathrm{Ca}$; PTH stimulates the osteoclasts to release bone calcium and VD3 increases $\mathrm{Ca}$ absorption from the gut. Moreover, PTH stimulates renal activation of 1 hydroxycholecaciferol to 1,25 dihydroxyvitamin D (VD3) ${ }^{[1]}$. There is a negative feedback mechanism between the PTH, VD3 and serum $\mathrm{Ca}$. The molecular mechanism through which the PG and kidney respond to changes in serum Ca was identified in 1993 as the extracellular Ca-sensing receptors (CaSR) ${ }^{[5]}$. Our patient did not have history of drugintake or low VD3. Her relatively high urinary $\mathrm{Ca}$, in face of severe hypoCa indicates renal rather than gut loss. She did not have evidence of intrinsic renal disease and hence the urinary $\mathrm{Ca}$ loss is PTH-mediated on distal nephrons. Three defects exist in HP; (a) PTH-resistance (pseudohypothyroidism) in which the PTH is high, (b) primary disease of the parathyroid glands in which the PTH level is undetectable, (c) defect in Ca-sensing receptors in which PTH is normal or mildly reduced. Normal PTH secretion and ultrasound of the parathyroid gland exclude its intrinsic damage and favors clinical diagnosis of defect in CaSR ${ }^{[6]}$. Moreover, our patient lacked; (a) familial or autosomal history of hypoCa, (b) multiple endocrinopathies, and (c) a childhood onset of disease (< 10 years). The latter 3 factors render APC 1 unlikely. The etiology of most hypoCa syndromes has been attributed to inherited gene defect or mutations except for (a) APC 1, and (b) acquired isolated hypocalcemic hypocalcuria which has autoimmune etiology ${ }^{[5]}$. The autoimmune etiology of acquired activating autoantibodies to CaSR was based on 3 observations; (a) detection of $12.9 \%$ CaSR antibodies in idiopathic hypoparathyroidism, (b) rarity of gene defects, and (c) cure of a patient and clearance of her functioning autoantibodies after treatment with high dose Prednisone and Azathioprine ${ }^{[5,7]}$. On the other side, the autoimmune theory and the significance of such autoantibodies has been questioned by other researchers ${ }^{[8]}$. Unfortunately, detection of autoantibodies to CaSR remains, at present, a research technology and hence, was difficult to be tested in our patient. To date, long-term high-dose calcium supplementation with high dose VD3 remains the practical therapy for this syndrome. However, clinical and periodic testing of urinary $\mathrm{Ca}$ output is essential to avoid $\mathrm{Ca}$ stone formation in predisposed patients ${ }^{[9]}$. Oral thiazide diuretics and even daily low dose subcutaneous PTH can be added if severe hypercalcuria hinders even symptomatic correction of hypoCa ${ }^{[10,11]}$. In the future targeting; (a) CaSR with calcilytic agents and (b) autoimmunity with immunosuppression may be the ideal treatment ${ }^{[12]}$. The beneficial role of later was recently reported in 2019 yet is limited in the literature to a single case report ${ }^{[7]}$. The concept is intriguing and deserves future studies.

\section{References}

[1] Anirban Bose, David A Bushinsky, Calcium Homeostasis, in Williams Textbook of Endocrinology (Thriteenth Edition), 2016.

[2] Betterle C, Garelli S, Presotto F. Diagnosis and classification of autoimmune parathyroid disease. Autoimmun Rev 2014; 13: 417-422.

[3] Meloni A, Willcox N, Meager A, Atzeni M, Wolff AS, et al. Autoimmune polyendocrine syndrome type 1: an extensive longitudinal study in Sardinian patients. J Clin Endocrinol Metab 2012; 97: 1114-1124.

[4] De Sanctis V, Soliman A, Fiscina B: Hypoparathyroidism: from diagnosis to treatment. Curr Opin Endocrinol Diabetes Obes 2012; 19: 435-442.

[5] Hendy GN, Canaff L. Calcium-Sensing Receptor Gene: Regulation of Expression. Front Physiol 2016; 7: 394435.

[6] Bilezikian JP, Khan A, Potts JT, et al. Hypoparathyroidism in adult: Epidemiology, diagnosis, pathophysiology, target-organ involvement, treatment, and challenges for future research. J Bone Miner Res 2011; 26: 2317-2337.

[7] Tomar N, Gupta N, Goswami R. Calcium-sensing receptor autoantibodies and idiopathic hypoparathyroidism. J Clin Endocrinol Met 2013; 98: 3884-3891, Chamberlin M, Kemp EH, Weetman AP, Khadka B, Brown EM. Immunosuppressive therapy of autoimmune hyperparathyroidism in a patient with activating autoantibodies against the calcium-sensing receptor. Clin Endocrinol 2019; 90: 214-221.

[8] Kemp EH, Habibullah M, Kluger N, Ranki A, Sandhu HK, Krohn KJ, Weetman AP. Prevalence and clinical associations of calcium-sensing receptor and NALP5 autoantibodies in Finnish APECED patients. J Clin Endocrinol Metab 2014; 99: 1064-1071.

[9] Curhan GC, Willett WC, Speizer FE, Stampfer MJ. Twenty-four-hour urine chemistries and the risk of stones among women and men. Kidney Int 2001; 59: 22902298.

[10] Porter RH, Cox BG, Heaney D, Hostetter TH, Stinebaugh BJ, Suki WN. Treatment of hypoparathyroid patients with chlorthalidone. N England J Med 1978; 298: 577-581.

[11] Brandi ML, Bilezikian JP, Shoback D, Bouillon R, Clarke BL, Thakker RV, Khan AA, PottsJT. Management of hypoparathyroidism: summary statement and guidelines. J Clin Endocrinol Metab 2016; 101: 2273-2283.

[12] John MR, Harfst E, Loeffler J, Belleli R, Mason J, et al. "AXT914 a novel, orally-active parathyroid hormonereleasing drug in two early studies of healthy volunteers and postmenopausal women". Bone 2014; 64: 204-210. 